\title{
TUTELA DA PREVENÇÃO AOS ACIDENTES DE CONSUMO NO CONTEXTO DA SEGURANÇA HUMANA
}

\section{PROTECTION OF THE PREVENTION CONSUMPTION OF ACCIDENTS IN THE CONTEXT OF HUMAN SECURITY}

\author{
${ }^{1}$ Francisco Glauberto Bezerra Junior \\ ${ }^{2}$ Ingrid de Lima Bezerra
}

\section{RESUMO}

O presente artigo destaca a tutela da prevenção aos acidentes de consumo no contexto da segurança humana. É apontada a mudança de paradigma do Desenvolvimento Humano e a transmutação do conceito de segurança pública para segurança humana, adotado pelo PNUD a partir da década de 90. Explana-se sobre os acidentes de consumo e a sua repercussão negativa para a coletividade em razão dos novos riscos. Indica-se a necessidade de que as políticas públicas que regulem os acidentes de consumo sejam contextualizadas na doutrina da segurança humana, objetivando criação de um sistema de proteção a saúde e segurança do consumidor.

Palavras-chave: Acidente; Consumo; Segurança Humana; Saúde; Consumidor.

\begin{abstract}
This article highlights the protection of the prevention of consumer accidents in the context of human security. It is pointed out the paradigm change of Human Development and the transmutation of the concept of public security for human security, adopted by the UNDP from the decade of 90. It is explained about the accidents of consumption and its negative repercussion for the community due to the new risks. It is pointed out the need for public policies that regulate consumer accidents to be contextualized in the doctrine of human security, aiming at the creation of a system of protection to the health and safety of the consumer.
\end{abstract}

Keywords: Accident; Consumption; Human Security; Health; Consumer.

\footnotetext{
${ }^{1}$ Mestrando em Direito e Desenvolvimento Sustentável pelo Centro Universitário de João Pessoa - UNIPÊ, Paraíba (Brasil). Professor pelo Centro Universitário de João Pessoa - UNIPÊ, Paraíba (Brasil).

E-mail: glaubertojr@gmail.com

${ }^{2}$ Mestre em Ciências Jurídico-Criminais pela Faculdade de Direito da Universidade de Lisboa - FDUL, Lisboa (Portugal). Professora pelo Centro Universitário de João Pessoa - UNIPÊ, Paraíba (Brasil).

E-mail: ingridbezerra@gmail.com
} 


\section{INTRODUÇÃO}

A relação Direito e Desenvolvimento é bastante problematizada, todavia, apesar das intensas discussões produzidas até o momento, tem-se, ainda, como atual e tencionada a trazer sempre mais frutos, dada a interdisciplinaridade imanente entre os seus objetos de pesquisa.

O Direito, em termos simplórios, pode ser visto como uma parcela da realidade social apreendida por determinadas normas. E o Desenvolvimento, mesmo sendo um conceito multidimensional, pode ser tratado como um processo de aprimoramento dessa realidade social, em outras palavras das condições da sociedade, vista em diferentes perspectivas.

A apreensão da conjugação desses conceitos, a priori, poderia trazer dificuldades de aplicação, mas, em verdade, relacionados corroboram a interligação dos seus objetos e as possibilidades de interações a depender das dimensões e bases utilizadas.

Dentro desta perspectiva, durante muito tempo, o pensamento dominante foi que Desenvolvimento e crescimento econômico seriam "a mesma face da moeda", ou seja, entendia-se que bastaria que determinada agrupamento social ou uma comunidade gerasse renda ou produzisse riqueza, medida pelo Produto Interno Bruto (PIB), para ser avaliada como desenvolvida.

Os fatos e o tempo demonstraram que no mundo real não é bem assim que o Desenvolvimento pode ser alcançado, ao contrário deve ser ampliado o empoderamento do indivíduo de forma multidimensional. Estudos de autores como Amartya Sen e Mahbuv ul Haq Tal, dentre outros, levaram o Programa das Nações Unidas para o Desenvolvimento (PNUD) a sugerir um novo conceito: o do Desenvolvimento Humano Sustentável (DHS).

Não se tratou apenas de trazer a tona um novo nome para Desenvolvimento através de um jogo de palavras, ao contrário, esse novo conceito resgatou importantes fundamentos e fez com que se centrassem as discussões sobre desenvolvimento em ideias sobre a humanidade, ou seja, o ser humano seria a razão de ser do Desenvolvimento e seriam no ser humano que deveriam se voltar tanto o processo quanto os resultados inerentes ao desenvolvimento.

Assim, desde 1990 o PNUD vem publicando Relatórios de Desenvolvimento Humano (RDHs) que demonstram essa nova forma de se abordar o desenvolvimento. Em seu relatório de 1994, desenvolvendo aspectos relacionados ao Desenvolvimento Humano, trouxe pela primeira vez a abordagem sobre a SEGURANÇA HUMANA (PNUD, 1994), rompendo paradigmas do tradicional conceito de segurança centrado no Estado armado, garantindo as variadas formas segurança individual e comunitária das pessoas e das sociedades. 
Partindo das concepções apresentadas, dentro do ordenamento jurídico brasileiro, pode ser destacado o Direito do Consumidor como instrumento para a compreensão do processo de desenvolvimento e igualmente para os modos e meios de promovê-lo, pautando-se exatamente por esse novo conceito de segurança humana.

Com efeito, com o surgimento da sociedade de consumo, ocorreram avanços significativos em vários âmbitos da sociedade, contudo, ao lado dos vários benefícios, sucederam determinadas dificuldades, como, por exemplo, o desequilíbrio entre os protagonistas das relações de consumo, ou seja, o consumidor tornou-se a parte manifestamente mais fraca, se submetendo, na maioria das vezes, ao arbítrio dos fornecedores, a parte realmente mais forte.

Por outro lado, identificaram-se, igualmente, nesta mesma sociedade de consumo as características de uma sociedade em que os riscos crescem cada vez mais, atingindo novos bens jurídicos, que prejudicam a saúde e segurança da própria sociedade, e, especialmente, do consumidor.

De fato, estes riscos atualmente não afetam apenas uma relação individual, ao contrário, eles ultrapassam barreiras de tempo e espaço e ocasionam danos incalculáveis a um grupo indeterminável de pessoas. Dentro desta perspectiva, os eventos danosos que afetam a saúde e segurança dos consumidores podem ser identificados como acidentes de consumo e na medida em que esses danos afetam toda a sociedade tem-se buscado novas formas de contenção desses riscos na tentativa de evitar os acidentes de consumo que afetam de forma concreta a própria a segurança humana.

Dessa forma, a tutela da prevenção de acidentes de consumo conforme instrumental trazido pelo Código de Defesa do Consumidor é mecanismo jurídico para a efetivação e realização da Segurança Humana, visto que na medida em que ocorre um acidente de consumo, o consumidor é afetado em sua saúde, integridade corporal, física ou psicológica, bem como tem diminuído seu patrimônio em decorrência de produtos ou serviços defeituosos.

Diante disto, a proposta deste trabalho não é esgotar a discussão sobre o tema do desenvolvimento, segurança humana, sociedade de risco e acidente de consumo, mas, tão somente, contribuir de alguma forma para a discussão da interação, procurando delimitações, enfatizando o paradoxo entre os novos riscos a serem tutelados e os princípios fundamentais do direito, especialmente do consumidor, relacionando a tutela da prevenção a acidentes de consumo no contexto da Segurança Humana. Para tanto são utilizados basicamente o método dedutivo e como técnica de pesquisa a documentação indireta: bibliográfica e documental. 


\section{DESENVOLVIMENTO COMO LIBERDADE NA SOCIEDADE DO RISCO: NOVO CONCEITO DE SEGURANÇA HUMANA.}

A sociedade pós-moderna vem sofrendo intensas e céleres transformações, decorrentes, em grande parte, da (r)evolução tecnológica. Tais transformações geraram grandes complexidades nas relações intersubjetivas e sociais, tanto em esfera nacional quanto global. Proporcionaram, ainda, novos avanços científicos e aperfeiçoaram a produção industrial.

Surgiram, em consequência desse panorama, novos riscos inerentes à fabricação, distribuição, utilização e difusão de como manusear produtos perigosos, como os advindos de técnica atômica, tecnologia genética, biotecnologia, dentre outros, não delimitáveis nem no espaço, nem no tempo, de forma a atingir não apenas um indivíduo, mas toda sociedade. Estes riscos são efeitos acessórios e secundários que desestruturam as ordens política, econômica e social (BECK, 1998).

É certo que os riscos e perigos, de maneira geral, sempre existiram no seio da sociedade, contudo, eram caracterizados como individuais, previsíveis, determináveis e exteriores àquela. $\mathrm{O}$ elemento caracterizador da sociedade atual, portanto, não é a existência do risco, mas a dimensão que este adquiriu, por conseguinte, na medida em que a sociedade se desenvolve, mais aumentam os riscos.

Atualmente, a sociedade pode ser denominada sociedade "do medo" ou "da insegurança sentida" (SILVA SÁNCHEZ, 2002, 33). Esta conceituação é bem alocada, pois não existem mais fronteiras para os riscos.

Logo, além de possuírem um grande potencial lesivo, ultrapassam os limites de tempo e espaço, causando danos sistemáticos e, por diversas vezes, irreversíveis, afetando diversas gerações e atingindo a sociedade tanto no âmbito local quanto mundial. Essas características posicionam os indivíduos em um estado de vulnerabilidade e desfavorecimento, pois, de acordo com o efeito boomerang, em qualquer lado que estiverem, seja como produtor de tecnologias, seja como usuário destas, se sujeita aos danos provocados.

Ressalte-se que a maioria dos riscos produzidos é consequência dos avanços tecnológicos, bem como da má utilização destas mesmas tecnologias. Como resultado há a deterioração da camada de ozônio, as mudanças climáticas, a desertificação, a instabilidade econômica, os ilícitos civis e penais cometidos por meio da Internet, dentre outros. 
Os bens jurídicos colocados em perigo na sociedade de risco são, em sua maioria, bens coletivos. A supraindividualidade do bem jurídico, contudo, não afasta a existência de interesses individuais, pois se todos os membros de uma sociedade forem prejudicados por práticas lesivas, não deixam cada um dos membros de serem também individualmente lesionados, possuindo, portanto, interesse legítimo na preservação dos bens jurídicos considerados individualmente (DIAS, 2004, p. 138).

É nesse contexto, com surgimento dos novos riscos, que se iniciam as discussões sobre a mudança de paradigma da segurança. Ou seja, a segurança tradicional que o Estado proporciona não é mais suficiente para suprir as necessidades sociais.

Por outro lado, deve-se destacar o pensamento exposto por Amartya Sen como um dos marcos teóricos fundamentais para a mudança de perspectiva dado ao Desenvolvimento pelo Programa Nacional das Nações Unidas, e, igualmente, para a fundamentação da Segurança Humana. É que Amartya Sem ao conceber o desenvolvimento centrado nas liberdades reais que as pessoas gozam e não apenas associando o desenvolvimento a fatores como o crescimento do Produto Interno Bruto, rendas pessoais, industrialização, avanço tecnológico ou modernização social, possibilitou que o Desenvolvimento fosse visualizado através de várias dimensões, voltando as atenções para os fins que tornam o desenvolvimento importante e não apenas aos meios, mas que igualmente desempenham papel relevante no processo (SEN, 2010, p. 16).

De tal modo, em 1994, o Programa das Nações Unidas para o Desenvolvimento PNUD trouxe pela primeira vez a ideia de segurança humana, centrada na sobrevivência, na segurança da vida diária e na dignidade da pessoa humana, tudo como embasamento para que o processo de Desenvolvimento fosse alcançado.

A partir de então, a Segurança Humana deve ser entendida como uma noção que promove respeito e proteção das pessoas, ou seja, o conceito prioriza o cumprimento das leis de defesa dos direitos humanos individuais, coletivos e difusos, enfatizando o aumento das liberdades das pessoas e colocando a livre condição de agente do ser humano não apenas como norte na condução do processo, mas como marco a ser, efetivamente, alcançado.

\subsection{Relatório sobre o Desenvolvimento Humano de 1994 do PNUD}

O Programa das Nações Unidas para o Desenvolvimento (PNUD), em seu relatório em 1994, trouxe pela primeira vez o conceito de segurança humana, rompendo paradigmas do 
tradicional conceito de segurança centrado no Estado, garantindo as variadas formas segurança individual e comunitária das pessoas e das sociedades.

Para o PNUD o conceito de segurança por muito tempo tem sido interpretado de forma restrita (enquanto segurança territorial contra agressões externa como proteção de interesses nacionais na política exterior ou como segurança mundial frente à ameaça nuclear). $\mathrm{O}$ conceito tradicional de segurança tem mais relação com o Estado do que com as pessoas (PNUD, 1994, 25).

De acordo com o Relatório do PNUD 1994, o mundo nunca poderá desfrutar da paz se não houver segurança na vida cotidiana dos indivíduos. Acrescenta que a busca de segurança humana deve efetuar através do desenvolvimento e não mediante armas (PNUD, 1994, p. 1).

O Relatório afirma que para a maioria das pessoas o sentimento de insegurança é mais decorrente das preocupações da vida cotidiana do que do medo de um cataclismo. As preocupações, portanto, são em relação à segurança do emprego, à segurança da saúde, à segurança do meio ambiente, à segurança em não haver delitos (PNUD, 1994, p. 3).

Para que as pessoas estejam seguram devem sentir-se livres de ameaças generalizadas e persistentes, violentas ou outro tipo, a seus direitos e sua segurança. A Segurança Humana abrange a proteção de riscos não tradicionais como ameaças à segurança da economia, da saúde, do meio ambiente, dentre outros.

O conceito básico de Segurança Humana deve centrar-se em quatro características essenciais (PNUD, 1994, p. 25/26):

a) Preocupação universal: A Segurança Humana é uma preocupação universal, atingindo tanto os países ricos como os pobres. As ameaças são comuns a todos, como o desemprego, as drogas, a violação dos direitos humanos, a criminalidade.

b) Componentes interdependentes: Quando a segurança da população está ameaçada em qualquer lugar do mundo, provavelmente que todos os países sejam afetados. Alguns fatos, como a fome, as doenças, o tráfico de drogas, o terrorismo, os conflitos étnicos, já não são acontecimentos isolados ultrapassando as fronteiras dos países.

c) Prevenção: A prevenção frente às ameaças possui um custo menor do que a repressão.

d) Ser humano: A Segurança Humana está centrada no ser humano. Preocupa-se com a maneira que as pessoas vivem em sociedade, com a liberdade de exercer suas opções, com o grau de acesso ao comércio, com as oportunidades sociais e com a vida em conflito ou em paz. 
Destaca-se no conceito de Segurança Humana que as pessoas devem ter condições de cuidar-se de si mesmas. Ou seja, todos devem ter oportunidades de satisfazer suas necessidades mais essenciais. Isto as libertará e ajudará a assegurar que podem contribuir eficazmente para o seu próprio desenvolvimento e de sua comunidade, seu país e do mundo (PNUD, 1994, p. 27).

Conforme o PNUD, a Segurança Humana possui dois enfoques: liberdade do medo (freedom from fear - proteger as pessoas de violências, tais como, guerras, genocídios e limpezas étnicas) e liberdade da necessidade (fredom from want - proteção das pessoas em relação às suas necessidades básicas, como fome, doenças). São, portanto, ameaças à segurança humana: o crescimento descontrolado da população, disparidades econômicas, migração internacional excessiva, deterioração do meio ambiente, produção e tráfico de drogas, terrorismo internacional (PNUD, 1994, p. 40).

Já para o Instituto Interamericano de Direito Humanos (IIDH), a segurança humana possui três enfoques: liberdade do medo (proteger as pessoas de ameaças diretas a sua segurança e integridade física); liberdade da necessidade (proteção das pessoas para que possam satisfazer suas necessidades básicas de sustento e aspectos econômicos); liberdade para viver com dignidade (proteção para que as pessoas possam viver sem violência, discriminação e exclusão. Reconhece ainda outras ameaças que podem afetar a sobrevivência, seus meios de vida ou sua dignidade).

Para o PNUD (1994, p. 28) o caráter transnacional dos riscos e problemas do mundo globalizado, influencia a Segurança Humana Mundial, motivo pelo qual, traz um conceito que abrange sete vertentes:

a) SEGURANÇA ECONÔMICA: Requer um ingresso básico assegurado, em geral, como resultado de um trabalho produtivo e remunerado ou em último recurso, de algum sistema de segurança financiado com recursos públicos. Atualmente cerca de um quarto da população possui segurança econômica (PNUD, 1994, p. 28).

b) SEGURANÇA ALIMENTAR: Significa que todos tenham acesso aos alimentos básicos. Sendo assim, não significa apenas que haja alimento suficiente para todos, mas que tenham acesso imediato a tais alimentos, seja por que tenham direito, seja porque cultiva, compram ou recebam de um sistema público de distribuição de alimentos. A disponibilidade de alimentos é uma condição necessária para a segurança, porém não é o suficiente. A oferta global de alimentos não é um problema, ou seja, há alimentos suficientes, porém, o problema consiste na má distribuição destes (PNUD, 1994, p. 30-31). 
c) SEGURANÇA À SAÚDE: Nos países em desenvolvimento as principais causas de falecimento são as doenças contagiosas e parasitárias; já nos países industrializados, são as doenças do sistema circulatório. Conforme o PNUD (1994, p. 31), tanto em países em desenvolvimento quanto nos industrializados, as ameaças à segurança da saúde são frequentemente maiores para os mais pobres, sobretudo as crianças e os habitantes das zonas rurais.

d) SEGURANÇA AMBIENTAL: As ameaças ao meio ambiente que os países enfrentam são uma combinação da deterioração dos ecossistemas locais e mundial. Muitas ameaças ambientais são crônicas e de efeito duradouro. Outras possuem um caráter mais súbito e violento (PNUD, 1994, p. 33).

e) SEGURANÇA PESSOAL: Em todos os países a vida humana está cada vez mais ameaçada pela violência súbita e imprevisível. Conforme o PNUD (1994, p. 34), são formas de ameaças: tortura física, guerra, conflitos étnicos, violência urbana, violência doméstica, violência contra crianças, tráfico de drogas, acidentes de trânsito e acidentes industriais.

f) SEGURANÇA DA COMUNIDADE: A maior parte da população tem sua segurança em virtude da participação de um grupo, de uma família, de uma comunidade, de uma organização. Os conflitos étnicos são considerados como principais ameaças à segurança comunitária (PNUD, 1994, p. 36).

g) SEGURANÇA POLÍTICA: Um dos aspectos mais importantes da segurança humana é o respeito aos direitos humanos fundamentais. Para o PNUD (1994, p. 37), um dos indicadores de insegurança política em um país é a priorização e utilização da força militar contra seus próprios nacionais.

Os problemas de Segurança Humana atingem escala mundial, pois as ameaças que surgem não se restringem a um único país, ou seja, as ameaças transpõem rapidamente as fronteiras (PNUD, 1994, p. 38).

A Comissão para a Segurança Humana (2003 p. 10-12) traz a seguinte definição de segurança humana

La seguridad humana consiste en proteger la esencia vital de todas las vidas humanas de uma forma que realce las libertades humanas y la plena realización del ser humano. Seguridad humana significa proteger las libertades fundamentales: libertades que constituyen la esencia de la vida. Significa proteger al ser humano contra las situaciones y las amenazas críticas (graves) y omnipresentes (generalizadas). Significa utilizar processos que se basan en la fortaleza y las aspiraciones del ser humano. Significa la creación de sistemas políticos, sociales, medioambientales, económicos, militares y 
culturales que en su conjunto brinden al ser humano las piedras angulares de la supervivencia, los medios de vida y la dignidade.

A Segurança Humana, muda, portanto, o foco da segurança tradicional, antes focada no Estado, para, agora, estar centrada no ser humano. Em verdade, a Segurança Humana complementa a segurança do Estado. Assim sendo, se estabelece a possibilidade de as pessoas viverem com qualidade de vida, de defenderem-se das ameaças e dos riscos que lhe afligem, de terem seus direitos humanos respeitados, enfim, de terem sua dignidade humana preservada.

\section{DIREITO DO CONSUMIDOR À VIDA, SAÚDE E SEGURANÇA E A PROBLEMÁTICA DOS ACIDENTES DE CONSUMO.}

A sociedade moderna tem como característica, dentre outras, a sua complexidade, traduzida no antagonismo existente entre os resultados advindos com sua chegada. Além de ter ocasionado progresso expressivo em vários domínios da coletividade, produzindo múltiplos benefícios, o surgimento da modernidade, igualmente, acarretou determinados problemas sociais para esta mesma sociedade, aos quais mereceram os reclamos de indivíduos e grupos das mais variadas camadas sociais (ALMEIDA, 2008, p. 23).

Um desses clamores pode ser identificado no âmbito das relações de consumo, em que as modificações foram intensas. Antes as relações que antes eram pessoais e diretas, se transformaram e passaram a ser impessoais e indiretas. A produção passou ser sistematizada e em massa, ocasionando, consequentemente, o consumo em massa, através da criação de novas necessidades. Tudo isso culminou na consciência de que o consumidor estava desprotegido diante dessa sociedade de consumo.

Nesta mesma sociedade, novos riscos foram criados e outros cresceram cada vez mais, atingindo novos bens jurídicos, que prejudicam a saúde e segurança da própria sociedade, e, especialmente, do consumidor. De fato, estes riscos atualmente não afetam apenas uma relação individual, ao contrário, eles ultrapassam barreiras de tempo e espaço e ocasionam danos incalculáveis a um grupo indeterminável de pessoas.

O consumo é inato ao ser humano, ou seja, diariamente, nas mais variadas situações, o ser humano está consumindo produtos ou serviços. Não por outro motivo que se considera apropriada, no âmbito da sociedade contemporânea, a afirmação de que "consumidores, somos todos nós”, atribuída ao Presidente John Kennedy, ao conhecido discurso que proferiu em 1962, 
nos Estados Unidos, ao enunciar a necessidade de proteção do consumidor (MIRAGEM, 2012, p.32).

Dentro dessa perspectiva pode-se evidenciar que

[...] a sociedade contemporânea se caracteriza pelo "fenômeno de massa", salientando que, do ponto de vista econômico, a produção é uma produção de massa, o comércio é de massa; o consumo, da mesma foram, tipicamente de massa. Isso significa dizer que o ato de uma pessoa ou de uma empresa envolve efeitos que atingem uma quantidade enorme de pessoa e categorias. No aspecto consumo, por exemplo, basta que um produto apresente um mínimo defeito, e já milhares ou milhões de consumidores sofrerão um dano. (ALMEIDA, 2008, p. 23)

Por vivermos, então, em uma sociedade do risco, em que vários produtos e serviços colocados no mercado podem ser nocivos e/ou perigosos à saúde e segurança do consumidor, garantir a proteção à vida, proteção à saúde e segurança contra estes riscos passa a ser fundamental.

Esses eventos danosos que afetam a saúde e segurança dos consumidores podem ser identificados como acidentes de consumo e, na medida em que esses danos afetam toda a sociedade, tem-se buscado novas formas de contenção desses riscos na tentativa de evitar os acidentes de consumo que afetam de forma concreta a própria a segurança humana.

Essa proteção do consumidor está vinculada ao princípio da dignidade da pessoa humana e, por esta razão, os direitos a saúde e segurança encontram-se como direitos básicos do consumidor, estando resguardados por vários dispositivos no Código de Defesa do Consumidor.

Deve ser sempre realçado que o direito do consumidor, com o advento da Constituição Federal de 1988, passou a ser considerado direito fundamental. O legislador constituinte incluiu explicitamente a defesa do consumidor no elenco dos direitos fundamentais no art. $5^{\circ}, \mathrm{XXXII}^{3}$ e, igualmente, como princípio da Ordem econômica, no art. $170^{4}$, como também destacou dentro da competência concorrente dos entes da Federação no art. $24^{5}$, todos da Constituição Federal e determinou que fosse elaborado um Código de Defesa do Consumidor, no art. 48 do

\footnotetext{
${ }^{3}$ Art. $5^{\circ}$. (omissis): XXXII - o Estado promoverá, na forma da lei, a defesa do consumidor;

4 Art. 170. A ordem econômica, fundada na valorização do trabalho humano e na livre iniciativa, tem por fim assegurar a todos existência digna, conforme os ditames da justiça social, observados os seguintes princípios: V defesa do consumidor;

5 Art. 24. Compete à União, aos Estados e ao Distrito Federal legislar concorrentemente sobre: VIII responsabilidade por dano ao meio ambiente, ao consumidor, a bens e direitos de valor artístico, estético, histórico, turístico e paisagístico;
} 
Ato das Disposições Constitucionais Transitórias - ADCT $^{6}$.

Em escólio aos dispositivos constitucionais, José Afonso da Silva anota:

Realça de importância (...) sua inserção entre os direitos fundamentais, com que se erigem os consumidores à categoria de titulares de direitos constitucionais fundamentais. Conjugue-se isso com a consideração do art. $170, \mathrm{~V}$, que eleva a defesa do consumidor à condição de princípio da ordem econômica. Tudo somado tem-se o relevante efeito de legitimar todas as medidas de intervenção estatal necessárias a assegurar a proteção prevista. (SILVA, 1990, p. 232)

O direito do consumidor recuperou a dimensão humana do consumidor, na medida em que o afirma como sujeito, titular de direitos constitucionalmente protegidos, bem como amplia sua proteção ao estabelecer vários instrumentos que protegem o consumidor em relação a sua vida, saúde e segurança.

Proteger o consumidor de todas as formas de transgressão dos seus direitos fundamentais, primordialmente, garantindo-lhe a dignidade da pessoa humana, é, na incisiva lição de Antônio Pinto Monteiro, "lutar pela qualidade do relacionamento humano, no que ele implica de respeito pela dignidade do Homem e pelo seu poder de autodeterminação, e no que ele significa de uma solidária e responsável participação na vida em comunidade" (MONTEIRO, 1996, p. 492).

E com o advento do Código de Defesa do Consumidor ao consagrar um novo microssistema de direitos e deveres inerentes às relações de consumo, aproximam de modo mais efetivo suas proposições normativas dos fatos da vida que regula (MIRAGEM, 2012, p. $41)$.

Com esse arcabouço legal, a segurança humana pode ser obtida de forma mais concreta, visto que para que os consumidores possam viver livres do medo de transgressões aos seus direitos fundamentais, como vida, saúde e segurança, os fornecedores devem observar as orientações dispostas no Código de Defesa do Consumidor (CDC), para que não ofereçam produtos e serviços que possam causar algum tipo de acidente de consumo.

A começar pelo art. $4^{\circ}$ deste diploma que afirma ser um dos objetivos da Política Nacional das Relações de Consumo o respeito à dignidade, saúde e segurança do consumidor.

\footnotetext{
${ }^{6}$ Art. 48. O Congresso Nacional, dentro de cento e vinte dias da promulgação da Constituição, elaborará código de defesa do consumidor.
} 
Além disso, esse mesmo artigo em seu inciso II, “d” e inciso $\mathrm{V}^{7}$, estabelece uma ação governamental visando proteger efetivamente o consumidor por meio da garantia dos produtos e serviços com padrões adequados de qualidade, segurança, durabilidade e desempenho e incentiva os fornecedores a elaborarem meios eficientes para o controle de qualidade e segurança de produtos e serviços.

O direito à vida, à saúde e à segurança é considerado bens de mais alta valia, por isso, estão de forma prioritária tutelada pelo CDC, inclusive em seu art. $6^{\circ}, \mathrm{I}^{8}$, que dispõe como direitos básicos do consumidor "a proteção da vida, saúde e segurança contra os riscos provocados por práticas no fornecimento de produtos e serviços considerados perigosos ou nocivos".

Esse assunto é tão importante que o legislador intitulou a Seção I, do Capítulo IV, como “Da Proteção à Saúde e Segurança". Nesta seção indica a nocividade e a periculosidade de produtos e serviços, quais os deveres de informação dos fornecedores em relação a nocividade e periculosidade dos produtos.

\section{Nesse sentido FILOMENO}

O direito à saúde, à segurança e à própria vida, portanto, são as primeiras preocupações do Código de Defesa do Consumidor, estabelecendo os deveres dos fornecedores. Primeiramente, o dever de informar a respeito de riscos que os produtos ou serviços prestados possam apresentar; em segundo lugar, a proibição de colocação no mercado de produtos e serviços que apresentem alto grau de nocividade ou periculosidade; em terceiro lugar, dever de comunicar às autoridades competentes que, após terem sido colocados no mercado, produtos e serviços apresentarem alto grau de periculosidade ou nocividade, bem como aos consumidores em geral; em quarto lugar, dever de retirar os produtos em questão do mercado, mediante o chamado recall. (FILOMENO, 2014, p. 39).

Ressalte-se que, em regra, os produtos e serviços inseridos no mercado não deverão

\footnotetext{
${ }^{7}$ Art. $4^{\text {o }}$ A Política Nacional das Relações de Consumo tem por objetivo o atendimento das necessidades dos consumidores, o respeito à sua dignidade, saúde e segurança, a proteção de seus interesses econômicos, a melhoria da sua qualidade de vida, bem como a transparência e harmonia das relações de consumo, atendidos os seguintes princípios:

II - ação governamental no sentido de proteger efetivamente o consumidor:

d) pela garantia dos produtos e serviços com padrões adequados de qualidade, segurança, durabilidade e desempenho.

V - incentivo à criação pelos fornecedores de meios eficientes de controle de qualidade e segurança de produtos e serviços, assim como de mecanismos alternativos de solução de conflitos de consumo;

8 Art. $6^{\circ}$ São direitos básicos do consumidor:

I - a proteção da vida, saúde e segurança contra os riscos provocados por práticas no fornecimento de produtos e serviços considerados perigosos ou nocivos;
} 
ocasionar risco à saúde ou segurança dos consumidores, contudo, poderão ser colocados no mercado produtos e serviços que tragam riscos desde que sejam previsíveis em razão da sua natureza e fruição.

Para ambos os casos os fornecedores são obrigados a prestar as informações necessárias de forma clara e adequada, contudo, neste último caso, em que os produtos trazem perigo, os fornecedores são obrigados a informar de forma ostensiva sobre a periculosidade ou nocividade do produto ou serviço, além de outras medidas.

De uma forma geral o Código de Defesa do Consumidor traz em seu art. $10^{9}$, a proteção à segurança do consumidor quando estabelece que o "fornecedor não poderá colocar no mercado de consumo produto ou serviço que sabe ou deveria saber apresentar alto grau de nocividade ou periculosidade à saúde ou segurança", neste caso, a nocividade e periculosidade não decorrem na natureza e fruição do produto ou serviço, mas sim é algo anômalo, passível de causar acidente de consumo.

No caso de o fornecedor inserir no mercado produtos ou serviços que posteriormente saiba da nocividade que apresentem, é obrigado a informar aos consumidores e às autoridades sobre o fato por meio de anúncios publicitários veiculados na imprensa, rádio e televisão, de forma a informar o maior número possível de consumidores. No caso de haver o recall, este deverá ser totalmente gratuito.

Todo o microssistema do Código de Defesa do Consumidor foi formulado para que o consumidor seja empoderado através da informação em relação aos perigos que os produtos e serviços podem oferecer. A transparência informacional é um dos mecanismos trazido pelo microssistema consumerista para que haja a prevenção ou minimização dos acidentes de consumo.

Por esta razão, por todo o CDC encontram-se artigos remetendo que os consumidores devem ser informados sobre os produtos e serviços. Nessa esteira, o art. $31^{10}$, preconiza que oferta e apresentação de produtos ou serviços devem assegurar informações com todas as qualidades necessárias, primordialmente sobre os riscos que apresentam à saúde e segurança dos consumidores.

\footnotetext{
${ }^{9}$ Art. 10. O fornecedor não poderá colocar no mercado de consumo produto ou serviço que sabe ou deveria saber apresentar alto grau de nocividade ou periculosidade à saúde ou segurança.

${ }^{10}$ Art. 31. A oferta e apresentação de produtos ou serviços devem assegurar informações corretas, claras, precisas, ostensivas e em língua portuguesa sobre suas características, qualidades, quantidade, composição, preço, garantia, prazos de validade e origem, entre outros dados, bem como sobre os riscos que apresentam à saúde e segurança dos consumidores
} 
Desta feita, como forma de evitar os acidentes de consumo, os fornecedores devem oferecer informações claras sobre o produto e serviço, sobretudo no que tange aos riscos que eventualmente apresentem à saúde e segurança dos consumidores.

$\mathrm{O}$ art. $12, \S 1^{\circ}, \mathrm{CDC}^{11}$, esclarece quando é considerado defeituoso o produto, qual sejam, aquele que não oferece a segurança que dele legitimamente se espera, levando-se em consideração as circunstâncias relevantes Por sua vez, o Art. 14, § $1^{\circ}, \mathrm{CDC}^{12}$, esclarece quando o serviço é considerado defeituoso, ou seja, quando não fornece a segurança que o consumidor dele pode esperar.

Embora haja uma preocupação do Código de Defesa do Consumidor em proteger a saúde e a segurança do consumidor, os acidentes de consumo são frequentes, além disso, muitos consumidores não sabem que o acidente ocorrido com algum produto ou serviço é configurado como acidente de consumo e que o fornecedor tem responsabilidade, há verdadeiramente uma violência silenciosa que não é percebida pela sociedade.

Considera-se acidente de consumo quando há um defeito no produto ou serviço que os tornam inadequados para uso, causando lesão ao consumidor, mesmo quando utilizados de forma adequada. Sendo assim, uma peça de um brinquedo engolida por uma criança, um corte feito por uma embalagem, arranhões em uma criança em virtude de partes pontiagudas em um carrinho de bebê, intoxicação alimentar, são exemplos de acidente de consumo.

Verifica-se que a colocação de produtos ou serviços nocivos ou perigosos à saúde e segurança é responsável pelos acidentes de consumos, motivo pelo qual os fornecedores devem seguir as disposições do CDC, orientando de forma eficaz o consumidor em relação à forma de

\footnotetext{
11 Art. 12. O fabricante, o produtor, o construtor, nacional ou estrangeiro, e o importador respondem, independentemente da existência de culpa, pela reparação dos danos causados aos consumidores por defeitos decorrentes de projeto, fabricação, construção, montagem, fórmulas, manipulação, apresentação ou acondicionamento de seus produtos, bem como por informações insuficientes ou inadequadas sobre sua utilização e riscos.

$\S 1^{\circ} \mathrm{O}$ produto é defeituoso quando não oferece a segurança que dele legitimamente se espera, levando-se em consideração as circunstâncias relevantes, entre as quais:

I - sua apresentação;

II - o uso e os riscos que razoavelmente dele se esperam;

III - a época em que foi colocado em circulação.

${ }^{12}$ Art. 14. O fornecedor de serviços responde, independentemente da existência de culpa, pela reparação dos danos causados aos consumidores por defeitos relativos à prestação dos serviços, bem como por informações insuficientes ou inadequadas sobre sua fruição e riscos.

$\S 1^{\circ} \mathrm{O}$ serviço é defeituoso quando não fornece a segurança que o consumidor dele pode esperar, levando-se em consideração as circunstâncias relevantes, entre as quais:

I - o modo de seu fornecimento;

II - o resultado e os riscos que razoavelmente dele se esperam;

III - a época em que foi fornecido.
} 
utilização do produto ou serviço, o risco de ocorrer acidentes de consumo diminui.

\section{TUTELA DA PREVENÇÃO DE ACIDENTE DE CONSUMO CONTEXTUALIZADA NA SEGURANÇA HUMANA: NECESSIDADE DE INTERAÇÃO ENTRE OS ÓRGÃOS ESTATAIS E OS CONSUMIDORES.}

O Código de Defesa do Consumidor parte do pressuposto que o consumidor é vulnerável, pois é a parte que possui menos informações acerca do produto ou serviço, não possui nenhum ou pouco poder quando do surgimento de um conflito entre este e o fornecedor. Além disso, é obrigado a submeter-se às práticas de mercado, mesmo às vezes sem ter noção nenhuma de tal fato. (FILOMENO, 2014, p. 3).

Por ser a parte mais vulnerável o Código de Defesa do Consumidor trouxe uma série de disposições para que fossem tuteladas a saúde e a segurança do consumidor. Quando há uma violação destes dispositivos, colocando produtos ou serviços perigosos à saúde e segurança, pode ocasionar os acidentes de consumo, sobretudo porque atualmente vive-se em uma sociedade de consumo em massa, em que há um consumismo exacerbado, aumentando as possibilidades da ocorrência desse tipo de acidentes.

Nesse sentido, deve a formulação da tutela da prevenção de acidentes de consumo ser centradas e, formuladas, com base no conceito de segurança humana. Ora, a segurança humana, em todas as suas acepções, tem o escopo prevenir ou minimizar eventos que podem prejudicar a sociedade atual e futura.

Sendo assim, para que os consumidores possam efetivamente viver livres de ameaças diretas a sua segurança, saúde e integridade física (liberdade do medo) e possam satisfazer suas necessidades básicas sem o perigo de que algum alimento consumido seja impróprio à saúde (liberdade de necessidade), necessário se faz a instituição de políticas públicas de segurança humana.

As politicas públicas embasadas no contexto da doutrina da segurança humana priorizam a produção de um sistema eficiente de tutela aos direitos básicos do consumidor, a exemplo da saúde e segurança.

Além de orientar os procedimentos administrativos e legais para efetivação da segurança humana, que é aquela segurança centrada no próprio ser humano. Isto porque deve ser observado que ocorrência de acidentes de consumo viola a segurança humana, na medida em que trazem eventos nocivos e perigosos para a saúde e segurança dos consumidores, os 
atuais e os futuros, no caso de o produto ou serviço não terem o problema sanado, ou não ser retirados do mercado, a tempo.

Uma das dificuldades em criar políticas públicas de prevenção ao acidente de consumo é que a maioria dos consumidores não sabe que sofreram ou estão a sofrer com risco a sua saúde e segurança que podem ocasionar os acidentes de consumo.

Sendo assim, por não terem consciência de que foram vítimas de acidente de consumo, os consumidores não reclamam perante aos fornecedores, nem perante aos órgãos de defesa do consumidor, existindo, portanto, uma cifra negra, em relação aos acidentes de consumo, o que dificulta uma efetiva política pública, além de impossibilitar a exigência para os fabricantes que façam as modificações necessárias dos produtos ou serviços a fim de seja sanados o defeito, ou, até mesmo, a retirada do produto ou serviço do mercado.

Dentro dessa perspectiva, sobressaem algumas politicas públicas que tenta, primeiramente, cientificar o consumidor da ocorrência de acidente de consumo e, ato contínuo, propalar a necessidade de que sejam notificados os órgãos estatais e o próprio mercado.

Neste sentido é a atuação da Secretaria Nacional do Consumidor que criou o Sistema de Informações de Acidentes de Consumo (SIAC). Neste sistema, as vitimas de acidente de consumo podem informar o evento danoso, criando de fato uma rede de proteção ao consumidor.

Ademais, como órgão coordenador do Sistema Nacional de Defesa do Consumidor, o Ministério da Justiça, por meio da Secretaria Nacional do Consumidor (SENACON), acompanha e fiscaliza todos os procedimentos de recall no Brasil, nos termos do artigo 10 do Código de Defesa do Consumidor, bem como desenvolve ações voltadas à prevenção de acidentes de consumo.

A importância dos temas relacionados à saúde e segurança motivou, inclusive, a criação de uma coordenação específica - a Coordenação de Saúde e Segurança do Consumidor -, na estrutura do Departamento de Proteção e Defesa do Consumidor.

E especificamente, com o intuito de regular a ação de recall ou processo de chamamento, o Ministério da Justiça regulamentou os procedimentos a serem seguidos pelos fornecedores ao se iniciar um recall.

Tendo em vista que o objetivo principal do procedimento é proteger a coletividade de riscos à saúde e segurança ocasionados por defeitos, um dos aspectos mais relevantes é a ampla e correta divulgação da campanha de mídia, de modo a garantir ao consumidor o direito à 
informação, bem como evitar ou minorar acidentes de consumo, por meio da divulgação de medidas preventivas e corretivas a serem tomadas pelo consumidor.

O recall também tem por objetivo reparar ou substituir o produto ou serviço defeituoso, de modo que o consumidor não tenha seu patrimônio diminuído ou sua expectativa frustrada. Entre outros objetivos do recall está, ainda, incluir a informação dos fatos à cadeia de fornecedores, clientes e consumidores, além dos órgãos competentes, sobre a natureza e a característica do risco, e apresentar de forma clara as ações para extingui-lo ou, ao menos, minimizar seus efeitos.

Tal minimização pode ser alcançada com a segregação do produto com vistas a prevenir distribuição ou a venda de unidades afetadas, ações para recolhimento, reparo, substituição ou reembolso dos produtos afetados, alteração do projeto do produto para sanar o defeito, ou destruição dos produtos afetados para garantir que não voltem ao mercado de consumo.

Por fim, igualmente, na vanguarda pela busca de interação entre poder público e sociedade, pode ser citada a atuação do Instituto Nacional de Metrologia, Qualidade e Tecnologia (Inmetro) que também possui em sua página na internet um local para que os consumidores vítimas de acidentes de consumo também possam relatá-lo.

Configura-se a partir da ideia de segurança humana a necessidade de abordagens da tutela de prevenção de acidentes de consumo que estejam centradas na remoção das principais fontes de privação da liberdade e de transgressões dos direitos fundamentais a vida, saúde e segurança dos consumidores.

Enfim, na tutela da prevenção de acidentes de consumo no contexto da segurança humana, o ser humano é colocado no centro da atuação estatal. Procura-se maximizar a efetivação da dignidade da pessoa humana através da proteção dos direitos fundamentais, como vida, saúde e segurança.

Para tanto, deve haver o alinhamento e a interação entre os indivíduos consumidores e os órgãos de proteção e defesa do consumidor para que possam acompanhar e monitorar as informações e propiciar politicas voltadas a segurança humana, com a eliminação do risco em suas localidades.

Com efeito, as estatísticas para a elaboração de um cadastro de acidentes de consumo a fim de seja utilizado para elaboração de políticas de prevenção de acidentes de consumo, são imprescindíveis as participações dos atores envolvidos que poderão descrever detalhadamente os acidentes de consumo ocorridos nas mais variadas situações, lugares e ocasiões. 


\section{CONSIDERAÇÕES FINAIS}

O presente artigo abordou algumas questões relativas aos aspectos gerais da sociedade de risco e a segurança humana, para posteriormente identificar o direito do consumidor a saúde e segurança como instrumento para tutela dos acidentes de consumo, e ao fim, realçar a necessidade de que esta tutela seja considera no contexto da segurança humana, objetivando produzir políticas públicas, através da interação entre o individuo e o poder público.

No transcurso do trabalho, constatou-se que, dentro do ordenamento jurídico brasileiro, o substrato normativo que dá azo a construção da tutela de prevenção aos acidentes de consumo deve ser buscado inicialmente na Carta Magna. O modelo constitucional, posto atualmente, ressalta a proteção do consumidor, nos artigos $5^{\circ}$, inciso XXXII, 170, inciso $\mathrm{V}$, da Constituição Federal de 1988 e no art. 48 do seu Ato das Disposições Constitucionais Transitórias. A inclusão da defesa do consumidor como direito fundamental na Carta Magna vincula o Estado e todos os demais operadores a aplicar e efetivar a defesa desse ente vulnerável, considerando mais fraco da sociedade.

Verificou-se, ainda, que concretizando as previsões constitucionais, o Código de Defesa do Consumidor - CDC (Lei $\mathrm{n}^{\circ}$ 8.078/90 que estabeleceu) criou um microssistema jurídico multidisciplinar na medida em que possui normas que regulam todos os aspectos da proteção do consumidor, coordenadas entre si, permitindo a visão de conjunto das relações de consumo.

Dentro desta perspectiva, os eventos danosos que afetam a saúde e segurança dos consumidores podem ser identificados como acidentes de consumo e na medida em que esses danos afetam toda a sociedade, tem-se buscado novas formas de contenção desses riscos na tentativa de evitar os acidentes de consumo que afetam de forma concreta a própria a segurança humana, visto que na concretização desta visão deve ser garantindo as variadas formas segurança individual e comunitária das pessoas e das sociedades.

Partindo das concepções apresentadas, dentro do ordenamento jurídico brasileiro pode ser destacado o Direito do Consumidor como instrumento para a compreensão do processo de desenvolvimento e igualmente para os modos e meios de promovê-lo.

E mais, a própria tutela da prevenção de acidentes de consumo seria instrumento prático e jurídico para a efetivação e realização da segurança humana, visto que quando ocorre um acidente de consumo, o consumidor é afetado em sua saúde, integridade corporal, física ou 
psicológica, bem como tem diminuído seu patrimônio em decorrência de produtos ou serviços defeituosos.

\section{REFERÊNCIAS}

ALMEIDA, João Batista de. A proteção jurídica do consumidor / João Batista de Almeida. - $6^{\text {a }}$ ed. rev., atual. e ampl. - São Paulo : Saraiva, 2008.

BECK, Ulrich. La sociedad del riesgo: Hacia una nueva modernidad. Barcelona: Paidós, 1998.

COMISIÓN PARA LA SEGURIDAD HUMANA (2003): La seguridade humana ahora. Informe final. Multi-Language Services Inc, Nueva York, 2003.

DIAS, Jorge de Figueiredo. Direito Penal - Parte Geral - Tomo I - Questões fundamentais. A doutrina geral do crime. Coimbra: Coimbra editora, 2004.

FILOMENO. José Geraldo Brito. Curso fundamental de direito do consumidor. $3^{\mathrm{a}}$ ed. São Paulo: Atlas, 2014.

INSTITUTO INTERAMERICANO DE DIREITO HUMANOS (IIDH). Disponível em: https://www.iidh.ed.cr/. Acesso em 15/07/2016.

INMETRO. Disponível em: http://www.inmetro.gov.br/consumidor/acidente_consumo.asp. Acesso em 05/08/2016.

MIRAGEM, Bruno. Curso de Direito do Consumidor / Bruno Miragem. - $3^{\mathrm{a}}$ ed. rev., atual. e ampl. - São Paulo : Editora Revista dos Tribunais, 2012.

MONTEIRO, Antônio Pinto. In Actas do Congresso Internacional sobre Comunicação e Defesa do Consumidor. Coimbra, 1996

SEM, Amartya. Desenvolvimento como liberdade / Amartya Sen ; tradução Laura Teixeira Mota ; revisão técnica Ricardo Doninelli Mendes. - São Paulo : Companhia das Letras, 2010.

SILVA, José Afonso da. Curso de direito constitucional positivo. São Paulo, RT, 6 ed., 1990.

SILVA SÁNCHEZ, Jesús-María. A expansão do direito penal: aspectos da política criminal nas sociedades pós-industriais. Trad. Luiz Otavio de Oliveira Rocha. São Paulo: Editora dos Tribunais, 2002.

PNUD. Informe sobre desarrollo humano 1994. México: Fundo de cultura económica, 1994 